\title{
En iaphtube, jornadas de sensibilización del Laboratorio Abierto de Patrimonio (LAP): \#PensandoEnAbierto
}

\author{
El Instituto Andaluz del Patrimonio Histórico (IAPH), en colaboración con la Asociación de Gestores \\ Culturales de Andalucía (GECA), organiza hasta el próximo mes de noviembre cinco jornadas de \\ sensibilización en las que se reflexionará sobre nuevos modelos de participación de la ciudadanía en la \\ gestión del patrimonio. La segunda jornada, "Espacios de coworking, cómo provocar sinergias", tendrá \\ lugar el próximo 26 de abril de 2017 y tendrá como ponente a Jaime Aranda, de WorkInCompany.
}

Instituto Andaluz del Patrimonio Histórico, Laboratorio Abierto de Patrimonio

URL de la contribución <www.iaph.es/revistaph/index.php/revistaph/article/view/3909>

El Laboratorio Abierto de Patrimonio (LAP) tiene su origen en 2016 a raíz de la participación del IAPH en el Proyecto Ambrosía (Food \& Drink) de la Fundación Europeana, la biblioteca digital europea que reúne fondos de reconocidas instituciones culturales de los 28 estados miembros de la Unión Europea. Uno de sus valores es que el contenido sea fácilmente utilizable y accesible, para que así la cultura sea un catalizador del cambio social y económico.

El LAP en el IAPH pretende ser una herramienta de apertura de la institución a través de los datos abiertos para conseguir el retorno social del conocimiento sobre patrimonio. Además persigue promover el modelo de gobierno abierto mediante la transparencia institucional, la colaboración y creación de redes con diferentes agentes, y la participación de la ciudadanía y los profesionales facilitando nuevas conexiones, que hasta ahora parecían improbables.

Durante 2017 se está desarrollando un programa con cinco jornadas de sensibilización con el objetivo de resituar la cultura en el nuevo contexto de participación e innovación en la gestión del patrimonio y que abordarán esta nueva filosofía que fomenta la participación ciudadana en la gestión del Patrimonio.

En la primera jornada, disponible en el canal iaphtube, "Filosofía Open desde la Administración Pública", se ha expuesto el caso de Citilab de Cornellá, un centro para la innovación social y digital. "Citilab es una mezcla

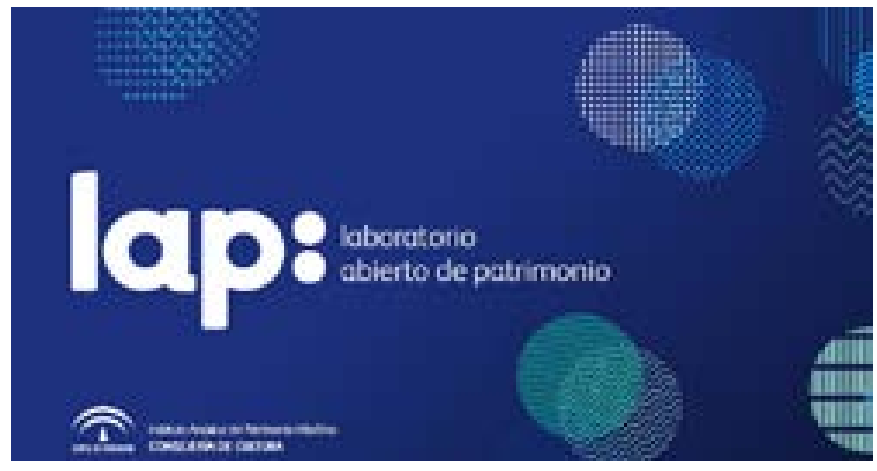

entre un centro de formación, un centro de investigación y una incubadora de iniciativas empresariales y sociales" según palabras de su director Artur Serra.

En este mes de abril se debatirá sobre los "Espacios de coworking, cómo provocar sinergias" en el sector de la cultura y el patrimonio y en mayo se abordará una reflexión sobre "¿Qué son datos abiertos? Aspectos legales y técnicos". Tras el verano se retomarán las jornadas con dos encuentros más: "Wikipedia como modelo de trabajo colaborativo para el bien común" e "Innovación en la cultura: hacia dónde caminamos".

Todos los encuentros están abiertos a la participación de profesionales de la cultura, estudiantes y ciudadanía. La inscripción es gratuita y puede gestionarse a través del correo-e. actividadeslap.iaph@juntadeandalucia.es. Información: http://www.iaph.es/web/canales/formacion/ lap/index.html 